(1)

\title{
Androgen actions via androgen receptor promote PTEN inactivation induced uterine cancer
}

\author{
Jaesung (Peter) Choi, Reena Desai, Yu Zheng, Mu Yao', Qihan Dong', Geoff Watson², \\ David J Handelsman and Ulla Simanainen
}

ANZAC Research Institute, University of Sydney, Sydney, New South Wales 2139, Australia

${ }^{1}$ Discipline of Endocrinology, Central Clinical School, Bosch Institute, Charles Perkins Centre, Royal Prince

Alfred Hospital, University of Sydney, Sydney, New South Wales 2050, Australia

${ }^{2}$ Department of Anatomical Pathology, Royal Prince Alfred Hospital, Sydney, New South Wales 2050, Australia
Correspondence should be addressed to D J Handelsman

Email

djh@anzac.edu.au

\begin{abstract}
Haploinsufficient inactivating phosphatase and tensin homolog (Pten) mutations cause Cowden syndrome, an autosomal dominant risk genotype for hormone dependent reproductive cancers. As androgen actions mediated via the androgen receptor (AR) supports uterine growth and may modify uterine cancer risk, we hypothesized that a functional AR may increase PTEN inactivation induced uterine cancer. To test the hypothesis, we compared the PTEN knockout (PTENKO) induced uterine pathology in heterozygous PTENKO and combined heterozygous PTEN and complete AR knockout (PTENARKO) female mice. PTENKO induced uterine pathology was significantly reduced by AR inactivation with severe macroscopic uterine pathology present in $21 \%$ of PTENARKO vs $46 \%$ of PTENKO at a median age of 45 weeks. This could be due to reduced stroma ER $\alpha$ expression in PTENARKO compared to PTENKO uterus, while AR inactivation did not modify PTEN or P-AKT levels. Unexpectedly, while progesterone $\left(P_{4}\right)$ is assumed protective in uterine cancers, serum $P_{4}$ was significantly higher in PTENKO females compared to WT, ARKO, and PTENARKO females consistent with more corpora lutea in PTENKO ovaries. Serum testosterone and ovarian estradiol were similar between all females. Hence, our results demonstrated AR inactivation mediated protection against PTENKO induced uterine pathology and suggests a potential role for antiandrogens in uterine cancer prevention and treatment.
\end{abstract}

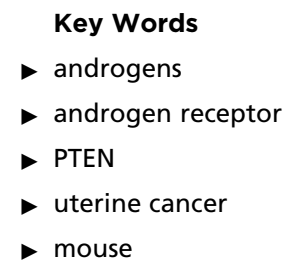

Endocrine-Related Cancer (2015) 22, 687-701

\section{Introduction}

Endometrial cancer (EC) is a frequent gynecological cancer. It is highly hormone dependent being promoted by estradiol $\left(\mathrm{E}_{2}\right)$ and inhibited by progesterone $\left(\mathrm{P}_{4}\right)$ (Bender et al. 2011), while the role of androgens remains controversial. Androgens are 19-carbon steroid hormones produced in females mainly by ovarian and adrenal gland secretion together with extraglandular conversion. Androgens mediate their effects via the androgen receptor (AR) expressed in target tissues such as the uterus of women (Somboonporn et al. 2004) and rodents (Walters et al. 2010). AR is a member of the nuclear receptor superfamily and encoded by an X chromosomal gene (Quigley et al. 1995). The biological effects of androgens in male physiology are well characterized, but the physiological roles in the female other than as precursors for conversion to estrogens by aromatase (Hillier et al. 1994) have only

Published by Bioscientifica Ltd. 
recently been recognized as critical for optimal female reproduction (Walters et al. 2007).

The possible role for androgens in uterine growth is supported by in vivo experimental findings. The nonaromatizable androgen, dihydrotestosterone (DHT), promotes growth and differentiation of the rodent uterus (Schmidt \& Katzenellenbogen 1979), whereas AR inactivation in mice resulted in a thinner uterus with a reduced total uterine area compared to WT females (Walters et al. 2009). However, in contrast, androstenedione (an aromatizable proandrogen) inhibited proliferation of human endometrial cells in vitro, an effect that was reversed by an antiandrogen (cyproterone acetate) suggesting these effects were mediated via AR actions in endometrial cells (Tuckerman et al. 2000). Androgens may also have a role in the development and/or progression of uterine carcinogenesis as increased androgen activity due to shorter CAG repeat in AR was related to an increased EC risk in women (McGrath et al. 2006). In addition, AR is strongly expressed in human endometrial disorders including different types of ECs (Ito et al. 2002), further supporting a role of androgens acting via AR in uterine cancer.

Phosphatase and tensin homolog (Pten) is a tumor suppressor gene located on chromosome 10 (Dahia 2000). Pten is mutated or deleted in a wide range of human cancers including breast and ECs (Dahia 2000). PTEN functions as a phosphatase and inhibits the growth factor signals transduced through PI3K by inhibiting AKT phosphorylation ( $\mathrm{Li}$ et al. 1998). Pten mutations are observed in $30-80 \%$ of type 1 ECs and in $20-70 \%$ of complex atypical hyperplasia, a premalignant stage of EC (Tashiro et al. 1997, Levine et al. 1998, Lee et al. 2012). Global homozygous PTEN inactivation is embryo lethal and the mice die between gestation days 6.5 and 9.5 (Suzuki et al. 1998). Global heterozygous Pten knockout (PTENKO) in mice resembles Cowden syndrome in patients and it causes EC, and therefore, PTENKO females are used as EC models (Stambolic et al. 2000). AR and PTEN interact in breast and prostate cancers (Wang et al. 2011) and they cross-regulate by reciprocal feedback (Carver et al. 2011, Mulholland et al. 2011). Furthermore, PTENKO increases ER $\alpha$ expression in EC cells (Lian et al. 2006) and activates ER $\alpha$ dependent pathways in mouse EC (Vilgelm et al. 2006).

The goal of this study was to investigate the role of AR-mediated androgen actions in PTEN inactivation induced experimental uterine cancer. To achieve our goal, we have generated and characterized global homozygous AR knockout (ARKO) females with or without global heterozygous PTEN inactivation using the Cre/LoxP system to determine the effects of AR inactivation on PTEN inactivation induced uterine cancer susceptibility and the possible mechanisms involved.

\section{Materials and methods}

\section{Mice}

All of the mice were housed under standard conditions $\left(19-22^{\circ} \mathrm{C}, 12 \mathrm{~h}\right.$ light:12 $\mathrm{h}$ darkness cycle) in cages with access to water and food ad libitum. For the generation of the WT (Cre negative littermate females with functional $\mathrm{AR}$ and PTEN denoted as WT), ARKO, PTENKO, and PTENARKO (combined heterozygous PTEN deletion and homozygous AR inactivation) models, three founding lines have been used: $\mathrm{Tg}$ (Sox2-cre)1Amc (denoted SOX2Cre (Hayashi et al. 2002)) kindly donated by Dr L Rob (Walter and Eliza Hall Institute) and Prof. A McMahon (Harvard University); Pten ${ }^{\text {tm } 1 \mathrm{Hwu}}$ mice (denoted PTENflox (Lesche et al. 2002)) lines with FBV/N genetic background; and $\mathrm{Ar}^{\mathrm{tm} 1 \mathrm{Jdz}}$ (denoted ARflox (Notini et al. 2005a)) line backcrossed to the $\mathrm{FVB} / \mathrm{N}$ background for at least six generations (originally C57Bl background). SOX2-Cre promoter is a universal deleter that is expressed from embryonic day 6.5 (Hayashi et al. 2002). To generate the experimental mice, the following breeding steps were used in a Cre/LoxP recombination strategy (Fig. 1A). First, a male mouse from the PTENflox mouse (Pten flox/ffox $)$ is crossed with a female from the ARflox mouse $\left(A r^{\text {flox } / w t}\right)$ to generate $P t e n^{\text {flox } / w t} A r^{\text {flox } / w t}$ females as well as $P t e n^{\text {flox } / w t}$ $A r^{\text {flox }}$ and $P t e n^{\text {flox } / w t} A r^{\mathrm{wt}}$ males. In step 2, a $P t e n^{\text {flox } / \mathrm{wt}}$ $A r^{\text {flox/wt }}$ female is crossed with a SOX2-Cre male mouse (Sox ${ }^{\text {cre } / \mathrm{cre}}$ ) to produce $P$ ten ${ }^{\mathrm{wt} / \mathrm{wt}} A r^{\mathrm{cut} / \mathrm{wt}} \mathrm{Cre}^{+/-}$and Pten $^{\mathrm{wt} / \mathrm{wt}}$ $A r^{\mathrm{ut} / \mathrm{wt}} \mathrm{Cre}^{+/-}$females in which the exon 3 of the floxed AR allele is deleted by Cre, creating AR cut allele.

\section{Experimental design and tissue collection}

Mice were sacrificed by cardiac exsanguination under ketamine/xylazine anesthesia at the mean age of 20 or 45 weeks. Body weight and reproductive organs (ovary and uterus), adrenal glands, spleen, and liver were dissected and weighed. Organs were either fixed (4\% paraformaldehyde at $4{ }^{\circ} \mathrm{C}$ overnight) for histological processing or snap frozen in liquid nitrogen for steroid analysis or mRNA extraction. Serum was separated and stored at $-20^{\circ} \mathrm{C}$. All of the procedures were approved by the Sydney South West Area Health Service Animal Welfare Committee within the National Health and Medical Research Council (NHMRC) guidelines for animal experimentation.

Published by Bioscientifica Ltd 


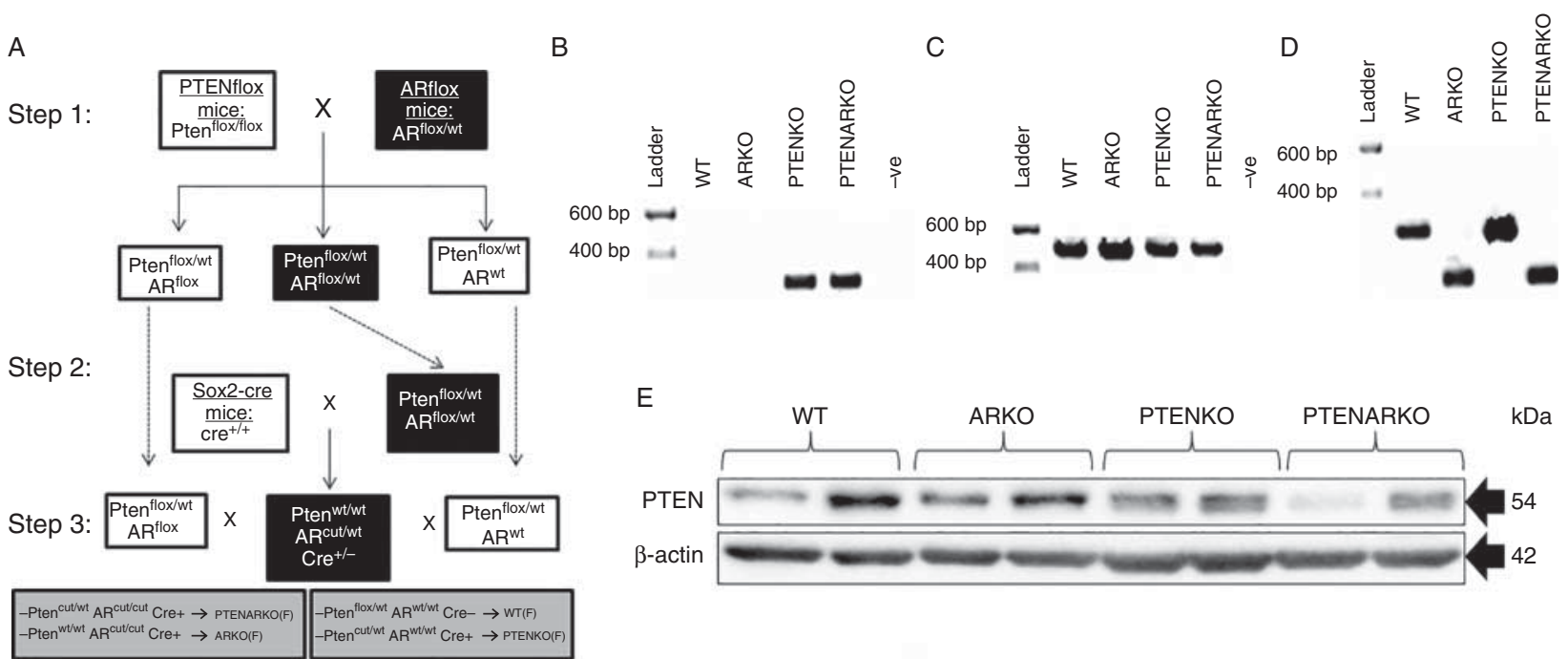

\section{Figure 1}

Breeding protocol and genotyping PCR on uterus CDNA. (A) White boxes represent male mice and black boxes represent female mice and grey boxes represent experimental groups. PTENflox mice have $\mathrm{AR}^{\mathrm{wt} / \mathrm{wt}}$ and $\mathrm{Cre}^{-1-}$ alleles, whereas ARflox mice have PTEN ${ }^{\mathrm{wt} / \mathrm{wt}}$ and $\mathrm{Cre}^{-l-}$ alleles. Sox $2 \mathrm{cre}$

\section{Genotype confirmation}

The excision of exon 5 in PTENKO and exon 3 in ARKO were confirmed at genomic DNA and mRNA levels. The genomic DNA was released using proteinase $\mathrm{K}$ digestion of uterine tissues. The excision of exon 5 of Pten was confirmed using the same primers as for genotyping (Byun et al. 2011). The excision of AR exon 3 was confirmed as described (Notini et al. 2005b). In addition, the excision of exon 3 of $A r$ in the uterus was confirmed by RT-PCR as previously described (Simanainen et al. 2007). Two product sizes were obtained: $288 \mathrm{bp}$ for intact $A r$ and $171 \mathrm{bp}$ for Cre-mediated exon 3 excised Ar. Exon 5 deletions in Pten was not confirmed by RT-PCR using RNA because exon 5 deletion in Pten produces stop codon; hence, no exons are produced after exon 4, meaning no bands will be produces at cDNA level. Two product sizes were obtained: $650 \mathrm{bp}$ for intact Pten and $300 \mathrm{bp}$ for Cre mediated exon 5 excised Pten. $\beta$-actin was used as a loading control.

\section{Ovariectomy and implants}

To determine the role of androgens in the uterine pathology in the controlled hormonal environment, PTENKO and PTENARKO mice were ovariectomized (OVX) under anesthesia at 5 weeks of age and implanted with $1 \mathrm{~cm}$ silastic implants (inner diameter $=1.47 \mathrm{~mm}$ and outer diameter $=1.95 \mathrm{~mm}$; Dow-Corning, Sydney, NSW, mice have $A R^{w t / w t}$ and PTEN ${ }^{w t / w t}$ alleles. (B) PTEN PCR showing PTEN deletion. (C) PTEN PCR showing WT PTEN. (D) ARCUT RT-PCR showing WT $A R$ and exon 3 excised AR. (E) PTEN western blot showing PTEN reduction in PTENKO and PTENARKO.

Australia) either containing $\sim 10 \mathrm{mg}$ crystalline testosterone or no steroid placed subdermally for 15 weeks and subsequently collected at 20 weeks of age.

\section{RNA extraction, DNase treatment, cDNA synthesis, and quantitative real-time RT-PCR}

RNA was extracted from the whole uterus from 20-weekold female mice. These procedures were performed as previously described (Simanainen et al. 2009). To measure mRNA expression of ER $\alpha$, lactoferrin, complement component 3 (C3), and glucose-6-phophate dehydrogenase $(G 6 P D H)$, the following primers were used: $E R \alpha$-forward (5'-ATGAAAGGCGGCATACGGAAAG-3') and $E R \alpha$-reverse (5'-CACCCATTTCATTTCGGCCTTC- $\left.{ }^{\prime}\right)$, lactoferrinforward (5'-CTAACCAGACCAGATCCTGCA-3') and lactoferrin-reverse (5'-CCTTCTCAGCCAGACACCTT-3'), C3-forward (5'-AACTGCTGGCCTCTGGAGTA-3') and C3reverse ( $5^{\prime}$-GCATGATTCCTCGAGGTTGT- $\left.3^{\prime}\right)$, and $G 6 P D H$ forward (5'-GCCTGGCATGTTCTTTAACC-3') and G6PDHreverse ( $5^{\prime}$-CAATCTTGTGCAGCAGTGGT-3'). Target genes were normalized to internal housekeeping gene $18 \mathrm{~s}$ rRNA. B-actin and hydroxymethylbilane synthase ( $\mathrm{Hmbs}$ ) were tested as housekeeping genes but $18 \mathrm{~s}$ rRNA was used because its expression was most consistent among the experimental groups. The following primers were used: $18 \mathrm{~s}$ rRNA-forward (5'-AACTTTCGATGGTAGTCGCCG-3') and $18 s$ rRNA-reverse ( $5^{\prime}$-AAACGGCTACCACATCCAAGG-3'),

Published by Bioscientifica Ltd. 
B-actin-forward (5'-AGCCATGTACGTAGCCATCC-3') and B-actin-reverse ( $5^{\prime}$-GGAACCGCTCGTTGCCAATA- $\left.3^{\prime}\right)$, and Hmbs-forward (5'-GGCAATGCGGCTGCAA-3') and Hmbs-reverse (5'-GGGTACCCACGCGAATCAC-3').

\section{Histology and immunohistochemistry}

A midsection (between the fimbrial end and cervical end) from a fixed uterine horn was embedded in paraffin and sectioned at $5 \mu \mathrm{m}$. Sections were either stained with hematoxylin and eosin (H\&E) for histopathological analyses or used for immunohistochemistry. Immunostaining was performed as previously described in Gao et al. (2014). The antibodies used were ER $\alpha$ (sc-542, Santa Cruz Biotechnology, 1:200 dilution), progesterone receptor (PR; sc-538, Santa Cruz Biotechnology, 1:100), PTEN (138G6, Cell Signaling, 1:50), AKT (11E7, Cell Signaling, 1:50), P-AKT (D9E, Cell Signaling, Danvers, MA, USA, 1:50), and p27 (sc-528, Santa Cruz Biotechnology, 1:50). The immunopositivity and immunointensity of $\mathrm{ER} \alpha$ were assessed by the $H$ score as previously described (McNamara et al. 2013). Different compartments of uterus were assessed separately: glandular epithelial cells, luminal epithelial cells, stroma, and myometrium. In brief, the $H$ score was obtained by assessing immunointensity (scales of $0-3$ ) and prevalence in 100 cells over five different areas in stroma and myometrium and prevalence in 20 cells over five different areas in glandular and luminal epithelial cells. All slides were counted twice to assess inter-observer variability.

\section{Protein extraction and western blot}

Proteins were extracted from the whole uterus from 20-week-old female mice and western blot was performed to measure PTEN, AKT, P-AKT, and p27 levels as previously described (Vignarajan et al. 2014). The antibodies used were PTEN (138G6, Cell Signaling, 1:500), AKT (sc-8312, Santa Cruz Biotechnology, 1:500), P-AKT (sc-7985, Santa Cruz Biotechnology, 1:300), p27 (sc-528, Santa Cruz Biotechnology, 1:500), and B-actin (ab8229, Abcam, Cambridge, UK, 1:3000).

\section{Uterine cancer classification}

All uteri from experimental mice were classified into two categories based on macroscopic characteristics: normal or abnormal. Normal uteri (Fig. 2A) had a uterine weight $<300 \mathrm{mg}$ and did not exhibit any macroscopic abnormalities such as extensive vascularization (Fig. 2B) or the presence of unusual growths (Fig. 2C). Abnormal uteri had a uterine weight $\geq 300 \mathrm{mg}$ (upper range of WT uterine weight mean \pm s.D.) resulting in enlarged uterine horns with any of the macroscopic abnormal features. Histopathological analysis of the macroscopic abnormal uteri was performed by a pathologist (Dr G Watson).

\section{Hormone assays}

Testosterone, $\mathrm{E}_{2}$, and $\mathrm{P}_{4}$ levels were measured in extracts of $100 \mu \mathrm{l}$ mouse serum and ovarian homogenates by liquid chromatography tandem mass spectrometry (LC-MS/MS; Harwood \& Handelsman 2009) as modified for mouse serum and ovary (McNamara et al. 2010). The lowest limits of quantification (defined as detectable with a coefficient of variation $<20 \%$ ) were $25 \mathrm{pg} / \mathrm{ml}$ for testosterone, $2.5 \mathrm{pg} / \mathrm{ml}$ for $\mathrm{E}_{2}$, and $50 \mathrm{pg} / \mathrm{ml}$ for $\mathrm{P}_{4}$.

\section{Corpus lutea count}

Ovaries were fixed and processed into glycol methacrylate resin (Technovit 7100; Heraeus Kulzer, Chatswood, NSW, Australia) and serially sectioned at $20 \mu \mathrm{m}$ and stained with periodic acid-Schiff. Corpus luteum (CL) was identified by morphological properties consistent with luteinized follicles and by being present in several serial sections. CL were counted on each ovary using an Olympus microscope with Stereo Investigator Software (MicroBright Field, Williston, VT, USA; Walters et al. 2009).

\section{Statistical analysis}

Statistics were performed by one-way ANOVA and twoway ANOVA with the least significant difference method for post hoc test using SPSS Software (SPSS, Inc.) unless stated otherwise. $P$ values smaller than 0.05 were considered statistically significant.

\section{Results}

\section{Confirmation of SOX2-Cre mediated excision of DNA between loxP sites of $\mathrm{Ar}$ and Pten}

PCR was used to confirm SOX2-Cre mediated excision of exon 3 of $A r$ and exon 5 of Pten in the uterus. The exon 5 deleted Pten PCR products (primers designed to amplify only the smaller exon 5 deleted product) were detected only in the uterus of PTENKO and PTENARKO mice (Fig. 1B), while only the native Pten product was detected in WT and ARKO uterus (Fig. 1C). However, the native Pten product was also detected in the PTENKO and PTENARKO

Published by Bioscientifica Ltd. 

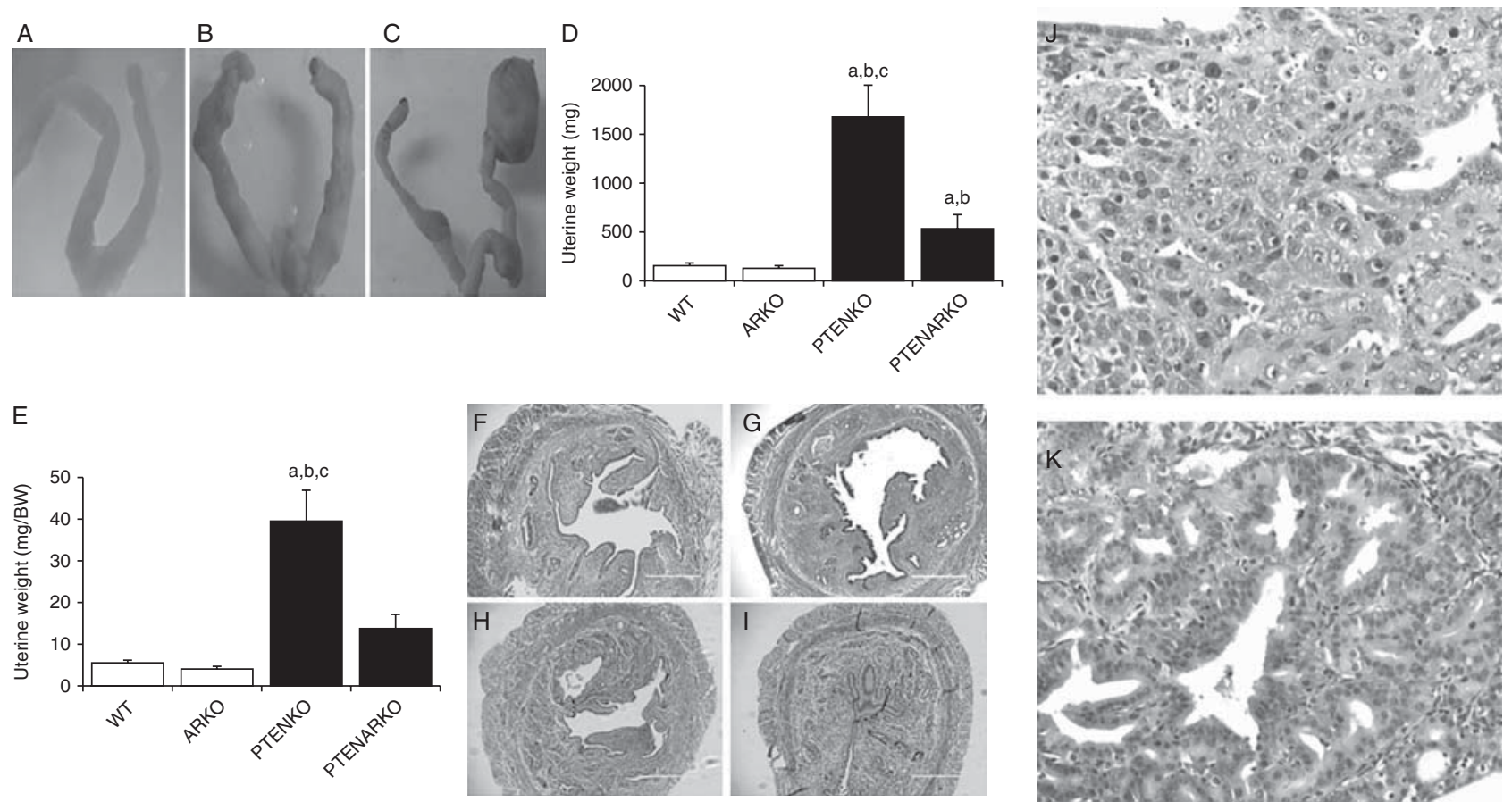

\section{Figure 2}

Uterus morphological classification at the median age of 45 weeks. (A, B and C) Representative images of macroscopic uterine category: normal uterus ( $A$ ) and abnormal uterus ( $B$ and $C$ ). ( $D$ and $E$ ) Absolute uterine weight (D) and standardized uterine weight (E). a Significantly different to $\mathrm{WT}$, ${ }^{\mathrm{b}}$ significantly different to ARKO, and 'significantly different to PTENARKO $(P<0.05$; one-way ANOVA); mean \pm s.E.M.

uterus as these mice were heterozygous for Pten deletion. In addition, the presence of native $A r$ (larger product containing exon 3) was confirmed in the WT and PTENKO female uterus at a cDNA level (RT-PCR), while the ARKO and PTENARKO uterus showed exclusively the smaller exon 3 deleted $\mathrm{Ar}$ products (Fig. 1D). Exon 5 excision in the Pten gene was not confirmed at the mRNA level because exon 5 excision produces stop codon and early termination of the transcription of mRNA.

Western blot was used to compare PTEN protein levels between the WT, ARKO, PTENKO, and PTENARKO uterus (Fig. 1E). While the PTEN levels were variable between individual uteri, the levels appeared to be decreased in the PTENKO and PTENARKO uterus (note PTENKO is heterozygous, thereby retaining a normal Pten allele) compared to the WT and ARKO uterus.

\section{AR inactivation modifies PTEN deletion induced uterine pathology}

All of the uteri of WT and ARKO females at the mean age of 43 and 46 weeks respectively were macroscopically
$(F, G, H$ and I) Representative images of normal uterus of WT (F), ARKO (G), PTENKO $(\mathrm{H})$, and PTENARKO $(\mathrm{I})$ at 45 weeks (scale bar $=400 \mu \mathrm{m})$. ( $\mathrm{K}$ and $\mathrm{K}$ ) Representative images of major uterine histopathologies in PTENKO and PTENARKO: high-grade carcinoma with dedifferentiated morphology (J) and low-grade (focal) adenocarcinoma (K).

normal. In PTENKO females, mean age of 46 weeks, $46 \%$ (24/52) had a macroscopic abnormal uterus compared to only $21 \%(5 / 24)$ in PTENARKO females, mean age of 43 weeks (Table 1). PTEN deletion significantly increased $(P<0.001$; log-linear model $)$ uterine cancer incidence, whereas AR inactivation significantly decreased $(P=0.0012)$ the PTEN induced uterine cancer incidence; interaction between PTEN deletion and AR inactivation was not statistically significant.

Comparable to pathology, uterine weights at 45 weeks was increased in PTENKO and PTENARKO compared to

Table 1 Macroscopic categorization of uterine abnormalities

\begin{tabular}{|c|c|c|c|}
\hline & No. of mice & $\begin{array}{l}\text { Age (weeks), } \\
\text { mean } \pm \text { s.D. }\end{array}$ & $\begin{array}{c}n(\%)^{\mathrm{a}} \text { of } \\
\text { abnormal uterus }\end{array}$ \\
\hline WT & 32 & $43 \pm 10$ & $0(0)$ \\
\hline ARKO & 14 & $46 \pm 9$ & $0(0)$ \\
\hline PTENKO & 52 & $46 \pm 8$ & $24(46)^{b}$ \\
\hline PTENARKO & 24 & $43 \pm 7$ & $5(21)$ \\
\hline
\end{tabular}

aPercentages shown are calculated over total number of mice. bSignificantly different to PTENARKO.

Published by Bioscientifica Ltd. 
WT and ARKO (Fig. 2D). The uterine weights were significantly increased $(P=0.004$; two-way ANOVA) by PTEN deletion but were not affected by AR inactivation $(P=0.077)$; interaction of PTEN deletion and AR inactivation was not significant $(P=0.091)$. Similar results were observed when uterine weights were standardized against the body weight (Fig. 2E). In addition, the PTENKO uterus was significantly heavier than the PTENARKO uterus. Uterine weights were similar between ARKO and WT females (Fig. 2D). Uteri that were categorized as normal in each genotype did not exhibit any abnormal histology and appeared similar (Fig. 2F, G, H and I).

Histopathological analysis of the macroscopic abnormal uteri showed different types of histopathologies. In PTENKO, 58\% (14/24) were high-grade (poorly differentiated) carcinoma, (Fig. 2J), 29\% (7/24) were low-grade adenocarcinoma (Fig. 2K) and the remaining 13\% (3/24) were endometritis, hematoma and an indeterminate tumor. In PTENARKO, only high-grade carcinoma $(3 / 5$, $60 \%$ ) and low-grade adenocarcinoma (2/5, 40\%) were observed. There was no statistically significant difference between PTENKO and PTENARKO in the distribution of histological grade among high-grade carcinoma and lowgrade adenocarcinoma.

Similarly to uterine weights at 45 weeks, uterine weights at 20 weeks were significantly increased
$(P=0.008$; two-way ANOVA) by PTEN deletion but were not affected by AR inactivation $(P=0.065)$; interaction of PTEN deletion and AR inactivation was significant $(P=0.009)$, with smaller uteri in PTENARKO than in PTENKO females (Fig. 3A). Histologically, no uterine cancers were detected at 20 weeks (Fig. 3B, C, D and E), although PTENKO uteri were histologically abnormal with enlarged and disorganized endometrial glands not present in uteri from other genotypes (Fig. 3D).

\section{AR-mediated androgen actions are required for testosterone-induced uterine regrowth}

OVX and testosterone treatment were performed on PTENKO and PTENARKO females to investigate the direct role of testosterone in the uterus (Fig. 4A). OVX prevented uterine growth in PTENKO and PTENARKO females with the uterine weights in OVX groups being about $15 \%$ of the intact female uterine weights at 20 weeks of age without any difference between the groups. In PTENKO females, testosterone treatments following OVX (OVX + testosterone) fully restored the uterine weight to the intact level at 20 weeks of age. However, no uterine growth was detected following OVX and testosterone treatment in PTENARKO females and the uterus weight remained similar to OVX-only females.
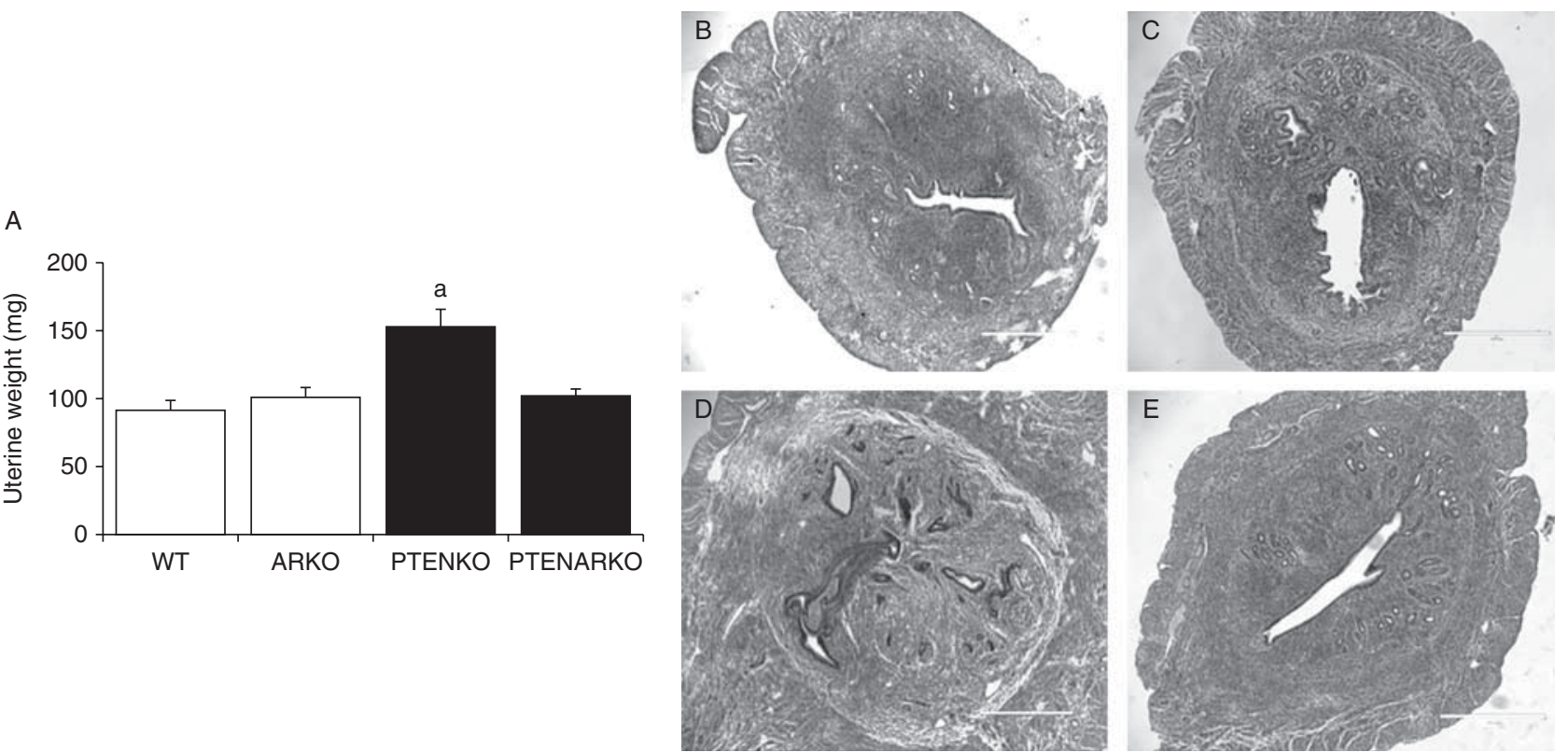

Figure 3

Uterine weight and histology (H\&E) at 20 weeks of age. (A) Uterine weight (mg). ${ }^{a}$ Significantly different to WT, ARKO, and PTENARKO $(P<0.05$; oneway ANOVA); mean \pm s.E.M.; $n \geq 8$. (B, C, D and E) Representative photos of
H\&E stained WT (B), ARKO (C), PTENKO (D), and PTENARKO (E) at 20 weeks (scale bar $=400 \mu \mathrm{m}$ ).

Published by Bioscientifica Ltd. 

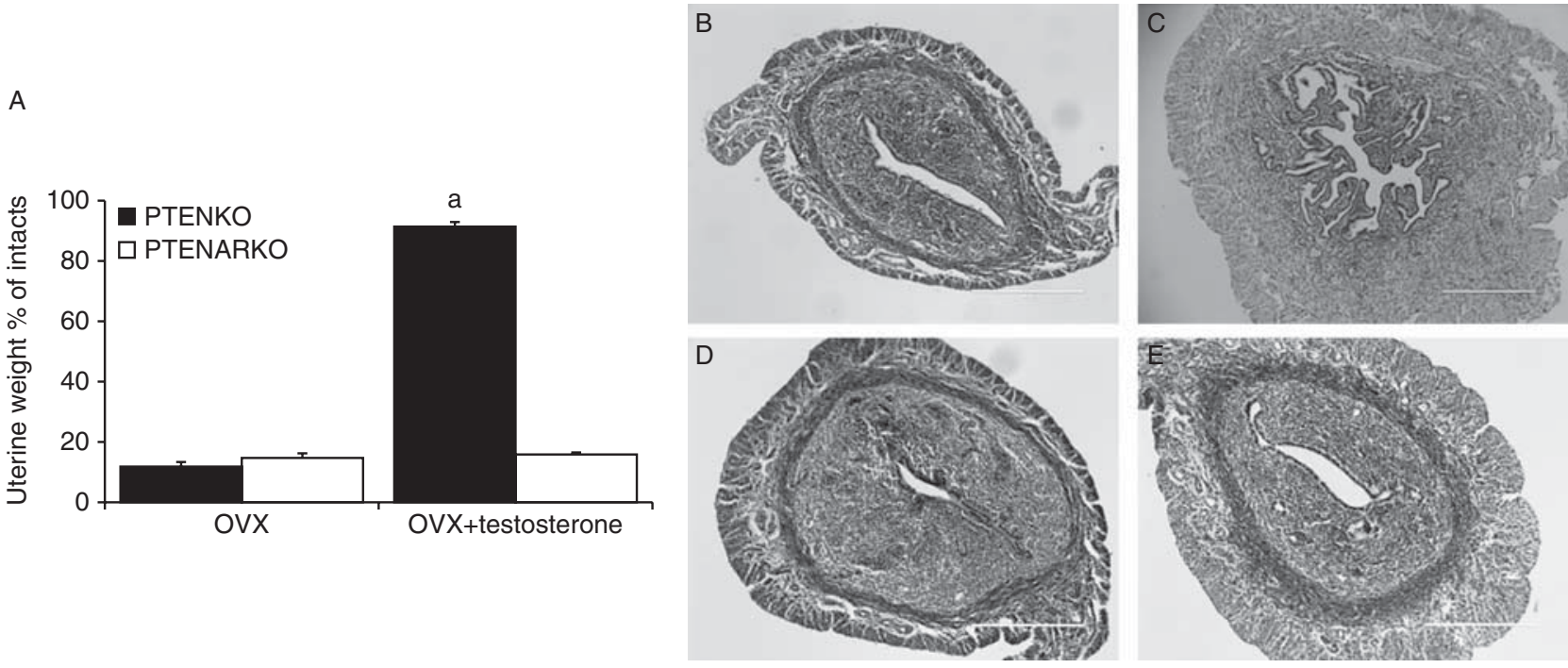

Figure 4

Uterine weight and histology (H\&E) at 20 weeks of age upon ovariectomy and testosterone treatment. (A) Uterine weight (relative to intact). ${ }^{a}$ Significantly different to OVX group and PTENARKO (OVX + testosterone) $(P<0.05$; one-way ANOVA); mean \pm s.E.M. (B, C, D and E) Representative

Histologically, the uteri of PTENKO (OVX), PTENARKO (OVX), and PTENARKO (OVX + testosterone) appeared similar (Fig. 4B, D and E).

\section{AR inactivation did not significantly affect PTEN, P-AKT, and p27 levels in the heterozygous PTEN-deleted uterus}

As it has been suggested that AR can regulate PTEN expression and, hence, modify the AKT pathway (Wang et al. 2011), we compared the PTEN, AKT, and P-AKT levels in the PTENKO and PTENARKO uterus. While no significant differences were found in the PTEN protein expression (Fig. 5A) between the PTENKO (native Ar) and PTENARKO (inactive $A r$ ) uterus, the AKT levels (Fig. 5B) were significantly increased $(P=0.02$; one-way ANOVA) in the PTENARKO uterus compared to PTENKO. However, the P-AKT (active form of AKT) levels (Fig. 5C) were not affected by the AR inactivation in the PTENKO uterus. As p27 is a key target of the growth regulatory activity exerted by the AKT pathway (Liang et al. 2002) and is deregulated in multiple cancers including the endometrioid uterus, the p27 protein, while reduced in PTENARKO (Fig. 5D), was not significantly different $(P=0.082)$ between the PTENKO and PTENARKO uterus. Immunohistochemically, no differences were observed in PTEN (Fig. 5E and F) and P-AKT (Fig. 5H and I) expression in the PTENKO and PTENARKO uterus in supporting the western blot results. photos of H\&E stained of PTENKO (OVX) (B), PTENKO (OVX+testosterone) (C), PTENARKO (OVX) (D), and PTENARKO (OVX + testosterone) (E) (scale bar $=200 \mu \mathrm{m}$ for image B, D, and E and $400 \mu \mathrm{m}$ for image C).

Whereas, all of the cells of the PTENKO were immunopositive for $\mathrm{p} 27$, whereas in the PTENARKO uterus, glandular epithelial cells were immunonegative supporting the lower protein levels observed by western blots (Fig. 5K and L).

To further examine the effect of androgens on PTEN, P-AKT, and p27 expression, we compared the levels between the PTENKO and PTENKO (OVX + testosterone) uterus. The OVX + testosterone-treated PTENARKO uterus was not included as the uteri were underdeveloped (Fig. 4). PTEN expression was decreased in all cells on OVX and testosterone treatment compared to intact PTENKO (Fig. 5G), whereas P-AKT expression was increased in glandular and luminal epithelial cells (Fig. 5J). p27 expression was increased in all cells on OVX and testosterone treatment in the PTENKO uterus compared to the intact PTENKO (Fig. 5M).

\section{Increased uterine ER $\alpha$ expression in PTENKO females was inhibited by simultaneous AR inactivation in PTENARKO females at 20 weeks}

As ER $\alpha$ expression is significantly increased in PTENKO uterus (Lian et al. 2006, Vilgelm et al. 2006), we examined if AR inactivation could influence this PTENKO induced increase in $\mathrm{ER} \alpha . \mathrm{ER} \alpha$ positivity (Fig. 6A) and intensity (Fig. 6B) were quantified according to different cell types:

Published by Bioscientifica Ltd 

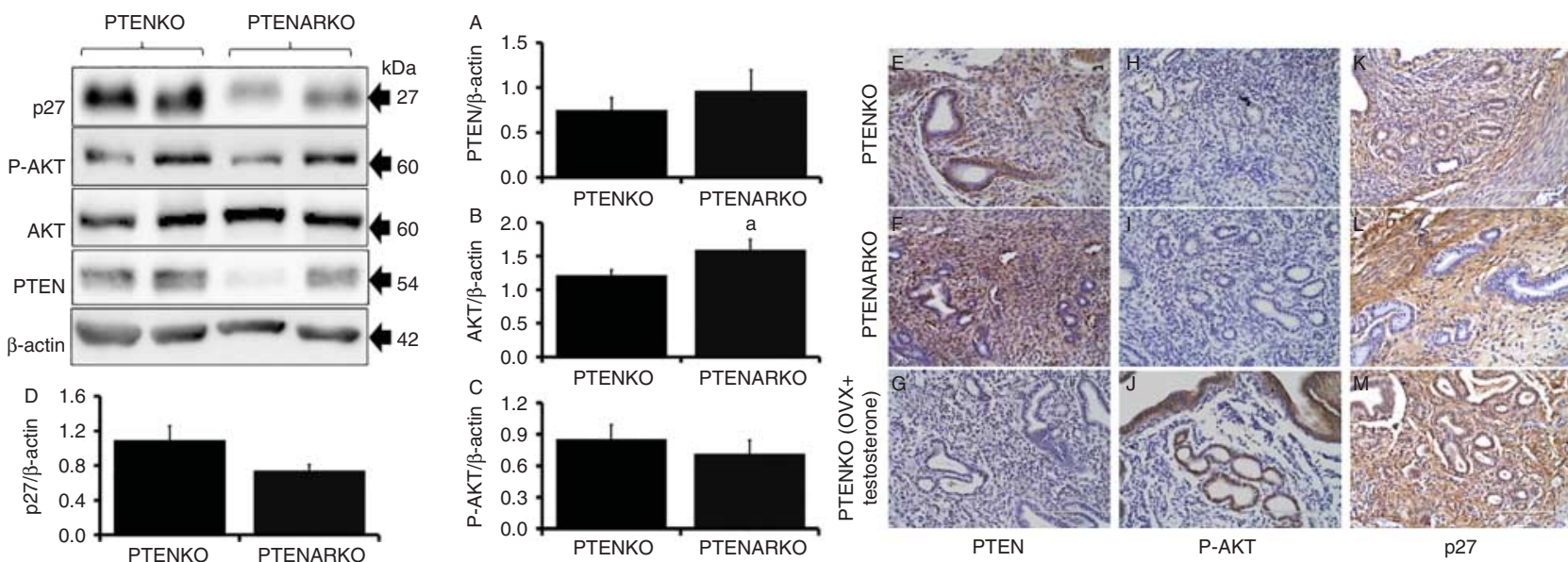

Figure 5

p27, AKT, P-AKT, and PTEN western blot and immunohistochemistry on PTEN deleted uterus at 20 weeks. Representative western blots for each protein are shown in the figure with the name of the protein labeled on the left and the protein band $(\mathrm{kDa})$ shown on the right. (A, B, C and D) Quantification of western blot bands by measuring the intensity of each

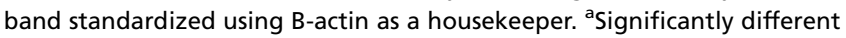

to PTENKO ( $P=0.043$; one-way ANOVA); mean \pm s.E.M.; $n \geq 5$. (E, F, G, H, I, J, $K, L$ and $M)$ Representative images of immunohistochemistry of PTEN, P-AKT, and P27 in PTENKO, PTENARKO, and PTENKO (OVX + testosterone) uterus at 20 weeks (scale bar $=100 \mu \mathrm{m}$ ). A full colour version of this figure is available at http://dx.doi.org/10.1530/ERC-15-0203.

$(P=0.002)$. A representative image of each genotype is shown in Fig. 6C, D, E and F.

Real time RT-PCR was performed to determine ER $\alpha$ gene expression. ER $\alpha$ mRNA expression was increased $(P=0.064$; one-way ANOVA) in the PTENKO uterus compared to WT, but this effect was prevented by simultaneous AR inactivation in the PTENARKO uterus (Fig. 6G). Congruent findings were observed in the expression of ER $\alpha$ target genes; G6PDH expression was
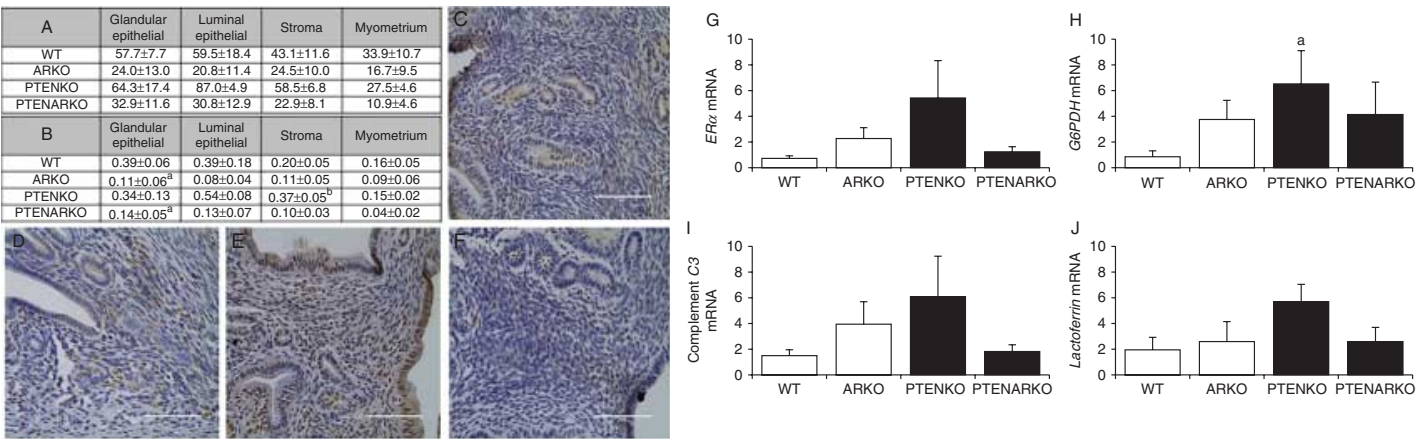

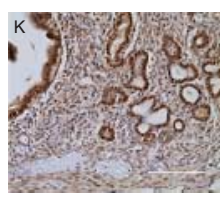

\section{Figure 6}

Expression of ER $\alpha$ and $E R \alpha$ dependent genes in the uterus of 20-week-old females. ( $A$ and $B$ ) Percentage of ER $\alpha$ positive cells (A) and intensity (B) in glandular epithelial cells, luminal epithelial cells, stroma, and myometrium in experimental groups. ${ }^{a}$ Significantly different to WT and ${ }^{b}$ significantly different to WT, ARKO, and PTENARKO (one-way ANOVA); mean \pm s.E.M.; $n=4$. (C, D, E and F) Representative images of ER $\alpha$ immunohistochemistry on WT (C), ARKO (D), PTENKO (E), and PTENARKO (F) (scale bar $=100 \mu \mathrm{m}$ ).
(G, $\mathrm{H}, \mathrm{I}$ and J) Relative expression (relative to $18 \mathrm{~s}$ rRNA housekeeping gene analyzed by real-time RT-PCR) of ER $\alpha$ mRNA (G) and Era-dependent genes $(\mathrm{H}, \mathrm{I}$ and $\mathrm{J})$ in the uterus at 20 weeks of age. ${ }^{a}$ Significantly different to WT $(P=0.019 ; t$-test); mean \pm s.E.M.; $n \geq 6$. (K) Representative image of $\mathrm{ER} \alpha$ immunohistochemistry on ovariectomized and testosterone-treated PTENKO uterus (scale bar $=100 \mu \mathrm{m}$ ). A full colour version of this figure is available at http://dx.doi.org/10.1530/ERC-15-0203. 
significantly increased $(P=0.019 ; t$-test $)$ in the PTENKO uterus compared to WT, and again this effect was prevented by simultaneous AR inactivation in the PTENARKO uterus (Fig. 6H). Although not statistically significant, other Era-dependent genes, lactoferrin $(P=0.064$; $t$-test; Fig. 6I) and complement C3 ( $P=0.097$; $t$-test; Fig. 6J) were also increased in the PTENKO uterus compared to WT and similarly this effect was prevented by simultaneous AR inactivation in the PTENARKO uterus.

Furthermore, when compared to the intact PTENKO uterus, the OVX + testosterone-treated PTENKO uterus had a marked increase in $\mathrm{ER} \alpha$ expression immunopositivity (Fig. 6K), which was observed in all of the cell types.

\section{PTENKO in females increased serum $\mathbf{P}_{\mathbf{4}}$}

As uterine cancer is highly hormone dependent (Martin et al. 1973a,b, Persson 1996), circulating sex steroid levels were investigated to determine if PTEN deletion and/or AR inactivation modified exposure to key reproductive hormones. Serum testosterone was not affected by genotype (Fig. 7A), whereas serum $\mathrm{P}_{4}$ (Fig. 7B) was significantly increased $(P=0.003$; two-way ANOVA) by PTEN deletion and significantly decreased $(P=0.008)$ by AR inactivation; interaction of PTEN deletion and AR inactivation was significant $(P=0.026)$, resulting in serum $\mathrm{P}_{4}$ being significantly increased in PTENKO compared to other groups.
In addition, the ovarian $\mathrm{E}_{2}$ content was analyzed, as serum $E_{2}$ in intact female mice is usually below the detection limit of LC-MS/MS (2.5 pg $\mathrm{E}_{2} / \mathrm{ml}$; McNamara et al. 2010). The ovarian $\mathrm{E}_{2}$ content was similar between the genotypes (Fig. 7C). Ovarian $\mathrm{P}_{4}$ (Fig. 7D) was also increased in PTENKO when compared to other genotypes; however, it was statistically non-significant due to the high variability in PTENKO.

Furthermore, as high levels of $\mathrm{P}_{4}$ are produced by the $\mathrm{CL}$ in the ovaries (Stocco et al. 2007) and PTEN is known to affect ovarian CL numbers (Fan et al. 2008), we quantified ovarian CL content in WT, ARKO, PTENKO, and PTENARKO females. The CL number was significantly reduced $(P=0.006$; two-way ANOVA) by AR inactivation and increased by PTEN deletion $(P=0.08)$; the significance of AR inactivation and PTEN deletion interaction was 0.053 (Fig. 7E and F), suggesting that increased $\mathrm{P}_{4}$ levels could be due to an increased CL number and that the increase in CL due to PTEN deletion was reversed by AR inactivation.

PR immunohistochemistry was performed on the PTENKO (Fig. 7G) and PTENARKO (Fig. 7H) uterus at 20 weeks and both the PTENKO and PTENARKO uterus expressed PR without obvious differences. However, compared to the intact PTENKO uterus, the OVX+ testosterone-treated PTENKO uterus had a marked increase in PR immunopositivity (Fig. 7I). This increase was observed in all cell types.
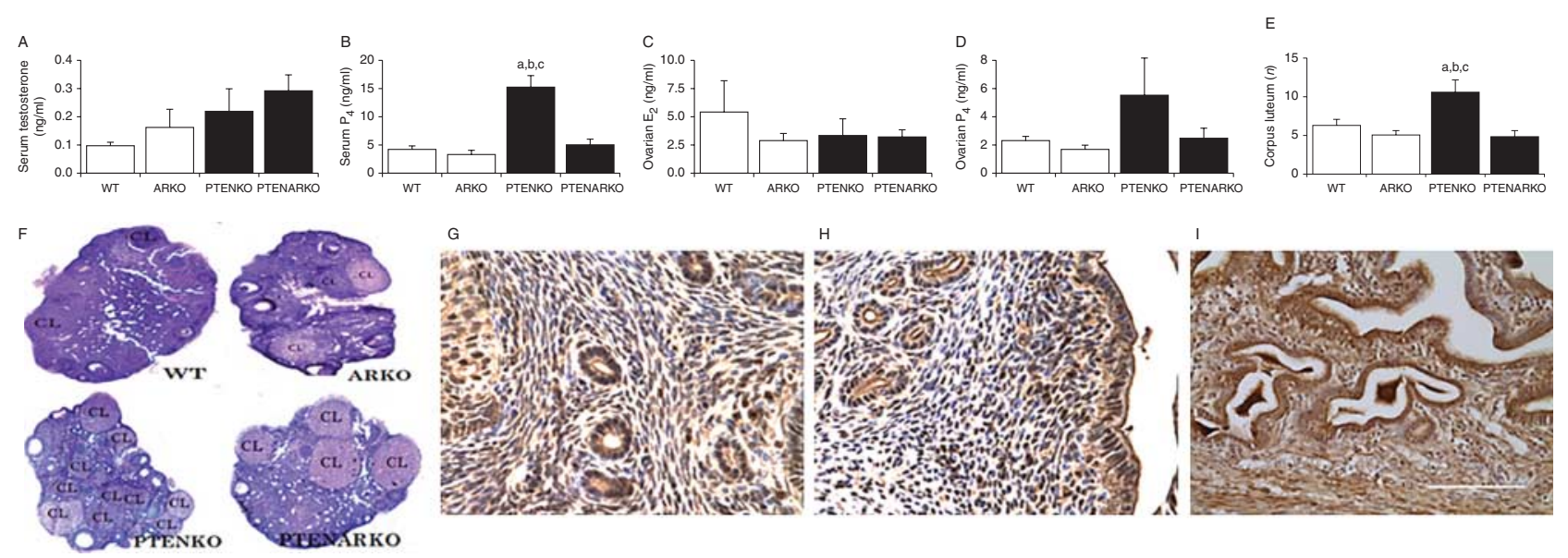

\section{Figure 7}

Steroid hormone levels and $\mathrm{CL}$ count at 45 weeks and PR expression in PTENKO and PTENARKO uterus at 20 weeks. Serum testosterone $(A)$ and $P_{4}$ (B) levels. ${ }^{a}$ Significantly different to $\mathrm{WT}$, ${ }^{\mathrm{b}}$ significantly different to ARKO, and 'significantly different to PTENARKO $(P<0.05$; one-way ANOVA); mean \pm s.e.M.; WT, $n=32$; ARKO, $n=7$; PTENKO, $n=43$; and PTENARKO, $n=23$. Ovarian $\mathrm{P}_{4}(\mathrm{C})$ and $\mathrm{E}_{2}(\mathrm{D})$ levels (mean \pm s.E.M.; $\left.n=4\right)$. ( $\mathrm{E}$ and $\mathrm{F}$ ) Total number of corpus luteum (CL) in ovaries of WT, ARKO, PTENKO, and
PTENARKO females with representative image. (F) a Significantly different to WT, 'b significantly different to ARKO, and 'significantly different to PTENARKO $(P<0.05$; nonparametric test); mean \pm s.E.M.; $n=4$. PR immunohistochemistry on PTENKO (G), PTENARKO $(\mathrm{H})$, and PTENKO (OVX + testosterone) (I) at 20 weeks old (scale bar $=100 \mu \mathrm{m})$. A full colour version of this figure is available at http://dx.doi.org/10.1530/ERC-15-0203.

Published by Bioscientifica Ltd 


\section{Multiple organs were affected by PTEN deletion and AR inactivation in females}

Body weight was significantly increased $(P<0.001$; twoway ANOVA) by PTEN deletion but AR inactivation did not affect body weight; interaction between PTEN deletion and AR inactivation was significant ( $P=0.001)$ (Fig. 8). As a result, other organ weights were evaluated with and without an adjustment for body weight.

Ovary and adrenal gland weights were significantly $(P<0.02)$ increased by PTEN deletion but were not affected by AR inactivation; there was no significant interaction between PTEN deletion and AR inactivation (Fig. 8). However, when adjusted for body weight, ovary weights were not affected by PTEN deletion, whereas the adrenal gland remained similar (Fig. 8). Absolute liver and spleen weights were not affected by AR inactivation and PTEN
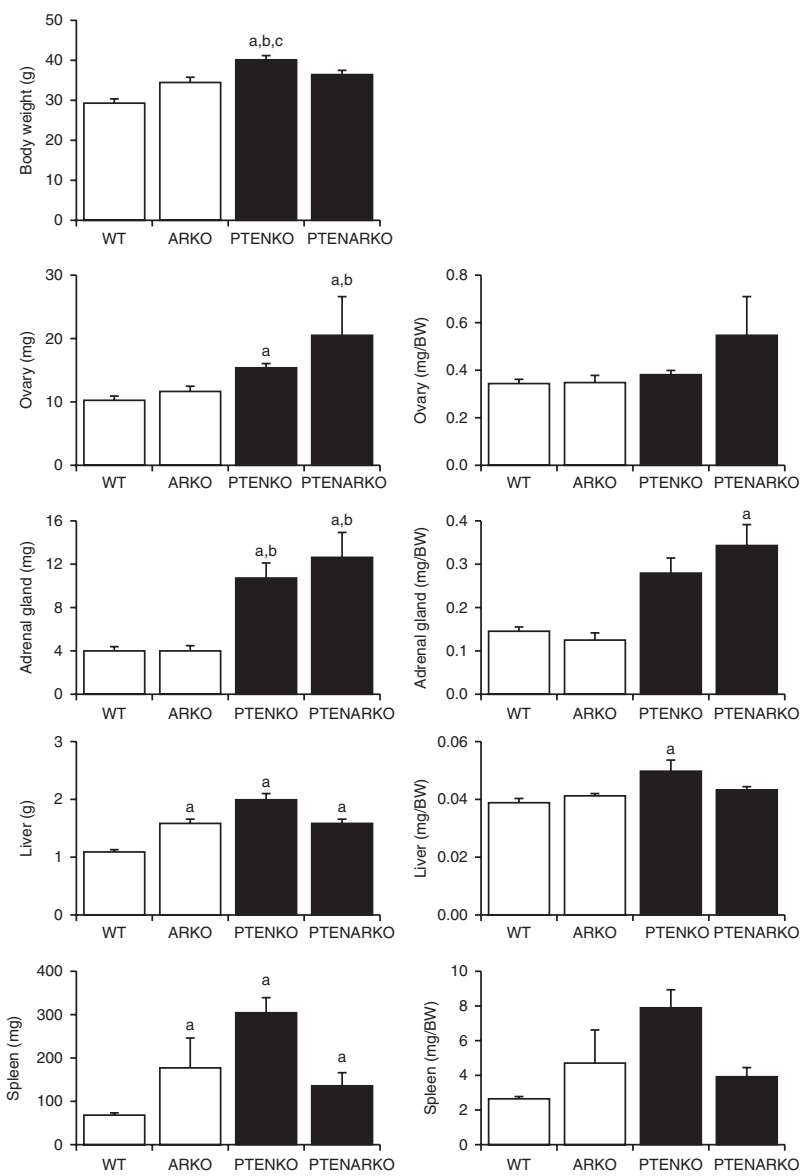

Figure 8

Body weight, absolute organ weights, and standardized organ weights of

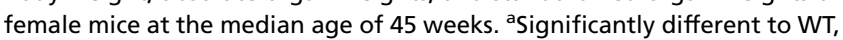
$\mathrm{b}^{\mathrm{b}}$ significantly different to ARKO, and 'significantly different to PTENARKO $(P<0.05$; one-way ANOVA); mean \pm s.E.M.; WT, $n=32$; ARKO, $n>7$; PTENKO, $n>43$; and PTENARKO, $n>23$. deletion; however, the interaction between AR inactivation and PTEN deletion was significant $(P<0.05)$ for both organs (Fig. 8). When adjusted for body weight only, the interaction between AR inactivation and PTEN deletion was significant (0.043) in the spleen but not in the liver (Fig. 8).

\section{Other incidental abnormalities}

Global heterozygous PTENKO also induced abnormalities other than uterine pathology in female mice (Table 2). Mammary gland abnormalities were the most frequent with 54\% of the PTENKO and PTENARKO females bearing abnormal mammary glands (palpable tumors or alveolarized mammary glands with milk production (Li et al. 2002)) compared with none detected in WT and ARKO. Histologically, the palpable tumors within the mammary glands were lymphomas ( $17 \%$ vs $21 \%$ in PTENKO vs PTENARKO) and fibroadenomas (23\% vs 30\%). In addition, some females had benign mammary abnormalities comprising alveolarized mammary glands with milk production (13\% vs $4 \%$; Table 2 ).

Very low frequencies of macroscopic abnormalities were also observed in the adrenal glands, liver, lung, ovaries, pancreas, and spleen (Table 2). Among these, the most frequent abnormality was the appearance of unusual black spots on the organ surface.

\section{Discussion}

Direct AR-mediated androgen actions on female reproductive physiology have been established (Walters et al. 2010) leading to suggestions that they may have an impact on the physiology and pathology of the uterus and breast (Somboonporn et al. 2004, Walters et al. 2010). As AR is expressed in the uterus of mice (Walters et al. 2010) and humans (Somboonporn et al. 2004), we explored the role of androgens acting via the AR in experimental, PTENKO induced murine uterine cancer. Our findings demonstrate that androgens acting via AR have a significant role in the uterine carcinogenesis, although it remains to be determined whether this is manifesting directly in the uterus or indirectly via systemic hormonal effects. We demonstrate that global AR inactivation significantly reduces the frequency of uterine cancers induced by PTEN deletion. Our findings also suggest that this preventive effect may be mediated by the elimination of a heterozygous PTENKO induced increase in uterine ER $\alpha$ expression. Furthermore, it is important to note that our uterine cancer model resembles Cowden syndrome, the germline mutation of

Published by Bioscientifica Ltd 
Table 2 Abnormalities found in 45-week-old experimental female mice. Percentages shown are calculated over total number of mice

\begin{tabular}{|c|c|c|c|}
\hline \multirow[b]{3}{*}{ Genotype } & \multirow[b]{3}{*}{ No. of mice } & \multicolumn{2}{|r|}{ Mammary } \\
\hline & & \multicolumn{2}{|c|}{ Palpable } \\
\hline & & Lymphoma & Fibroadenoma \\
\hline WT & 32 & NA & NA \\
\hline ARKO & 11 & NA & NA \\
\hline PTENKO & 52 & $9(17 \%)$ & $12(23 \%)$ \\
\hline PTENARKO & 24 & $5(21 \%)$ & $7(30 \%)$ \\
\hline
\end{tabular}

one allele of PTEN resulting in hereditary cancer predisposition (Liaw et al. 1997). Hence, the prevention of uterine cancers by interrupting androgen action in our model may not only represent an effective simulation of the ECs in Cowden syndrome but also point to the potential role of antiandrogens in its treatment.

This study demonstrates that androgens acting via AR decrease uterine cancer incidence in a PTENKO experimental uterine cancer model. The heterozygous PTENKO induced uterine cancers as previously reported (Risinger et al. 1997, Stambolic et al. 2000). However, these changes in the PTENKO uterus were significantly reduced by AR inactivation in PTENARKO females. Our findings also suggest that the AR inactivation slows the carcinogenic process, as at 20 weeks of age PTENKO females showed only premalignant uterine hyperplasia, a premalignant precursor to EC. While not experimentally tested before, an influence of androgens on uterine cancer development is consistent with a previous clinical study showing an excess of a shorter CAG repeat in the AR gene, which increases tissue androgen sensitivity (Simanainen et al. 2011), being associated with an increased EC risk (McGrath et al. 2006). Furthermore, there is also evidence that polycystic ovary syndrome (PCOS) patients with elevated plasma androgens (Nagamani et al. 1986) have an increased risk of uterine cancer (Smyczek-Gargya \& Geppert 1992). Also, our study has shown AR-mediated uterine regrowth upon ovariectomy and testosterone treatment.

In breast and prostate cancers the $\mathrm{AR}$ is suggested to regulate the PTEN levels (Wang et al. 2011), and therefore, we determined if the PTEN expression was modified by AR inactivation in the PTENARKO uterus and could therefore modify the risk of uterine cancer. However, we were unable to detect a significant effect of AR inactivation on PTEN gene expression in the uterus. However, the total AKT levels were significantly increased in the PTENARKO uterus when compared to PTENKO, whereas the active phosphorylated AKT levels were unaffected. These findings suggest that the reduced uterine cancer incidence in PTENARKO females may not be due to the modification of the AKT signaling pathway. Yet, in prostate cancer cells, AR-mediated protection from PTEN induced apoptosis is independent of AKT pathway activation (Li et al. 2001). In addition, our study showed diminished PTEN expression in the PTEN (OVX + testosterone) uterus compared to the intact suggesting that testosterone alone, in the absence of other steroid hormones, negatively regulate PTEN expression in the uterus. This was supported in a prostate cancer cell study, in which DHT via AR inhibited PTEN transcription and translation (Wang et al. 2011). Diminished PTEN expression in the PTENKO (OVX+ testosterone) uterus resulted in an increased P-AKT expression in glandular and luminal epithelial cells, supporting previous reports of negative correlation between PTEN and P-AKT in the uterus (Stambolic et al. 1998, 2000). Hence, further investigations are warranted to examine AR and PTEN interaction in the origins of uterine cancers.

Interestingly, we found that the expression of the tumor suppressor p27 appeared to be reduced $(P=0.082)$ in the PTENARKO uterus when compared to PTENKO. This could be due to a reduced p27 expression in glandular epithelial cells of the PTENARKO uterus. This was unexpected as the p27 levels are usually negatively correlated with malignancy with the level of p27 being reduced in $\sim 50 \%$ of human cancers (Sgambato et al. 2000, Slingerland \& Pagano 2000). However, our finding suggesting a positive correlation between p27 expression and uterine cancer was supported by a clinical studies where p27 expression was increased in patients with endometrioid adenocarcinomas (Watanabe et al. 2002) and advanced grading EC (Nycum et al. 2001). However, contrary to our findings, other clinical studies reported a negative correlation between $\mathrm{p} 27$ expression and uterine cancers (An et al. 2002). Hence, our study is the first experimental evidence suggesting the positive correlation between p 27 and uterine cancer. The increased p27 could be

Published by Bioscientifica Ltd. 
due to a compensatory mechanism, as a tumor suppressor gene combating uterine cancer rather than causing uterine cancer, which warrants further investigations.

Furthermore, we have shown an increased p27 expression throughout the OVX + testosterone PTENKO uterus compared to the PTENKO uterus suggesting testosterone alone, in absence of other steroid hormones, can upregulate p27 expression in the uterus. Yet, in prostate cancer and epithelial cells, a negative correlation was observed between androgens and p27 expression (Waltregny et al. 2001, Fang et al. 2012). The most widely accepted mechanism of increased risk for uterine cancer in PCOS patients is that of excessive unopposed estrogen exposure (Gambrell et al. 1983) as these women have persistent circulating $\mathrm{E}_{2}$ levels; however, as they are frequently anovulatory, they lack the usual $\mathrm{P}_{4}$ opposition against excessive estrogen action (Lobo et al. 1981). While we were unable to measure serum $\mathrm{E}_{2}$ concentrations as they were below sensitivity of our LC-MS/MS methodology (limit of quantitation $2.5 \mathrm{pg} / \mathrm{ml}$ ), ovarian $\mathrm{E}_{2}$ content was not significantly different between the genotypes suggesting the circulating $\mathrm{E}_{2}$ levels were probably similar for each genotype. Furthermore, serum testosterone levels did not differ according to genotype. However, as testosterone could be aromatized within the uterus (Huhtinen et al. 2012), the uterine content of $E_{2}$ should be analyzed in the future. In addition, while an exclusively direct role of androgens has not been confirmed, AR expression is increased in the endometrium of women with PCOS, suggesting the direct AR-mediated androgen actions in uterine carcinogenesis (Apparao et al. 2002). AR is also strongly expressed in various endometrial disorders including different types of ECs (Ito et al. 2002), further supporting a role of androgens acting via AR. These findings raise the hypothesis that antiandrogens may have an unrecognized role in the prevention and early stages of uterine carcinogenesis or in treatment.

Interestingly, the increased uterine estrogen sensitivity due to the PTEN inactivation in PTENKO females corresponded to an increasing expression of not only ER $\alpha$ but also a variety of estrogen sensitive target genes (lactoferrin, G6PDH, and complement C3) in the PTENKO uterus. However, further analysis is warranted to determine if the increase in estrogen-regulated genes in the PTENKO uterus is due to increased estrogen sensitivity or increased epithelial cell numbers. This finding extends to an in vivo model and previous in vitro study in which PTEN inactivation increased $\mathrm{ER} \alpha$ expression (Lian et al. 2006). Similarly, the loss of Pten and subsequent AKT activation in the uterus was shown to activate Era-dependent pathways in mouse EC (Vilgelm et al. 2006). Furthermore, our findings suggest that the reduced uterine pathology following AR inactivation in PTENARKO females could be due to a reduced ER $\alpha$ expression, consistent with the reduced $\mathrm{ER} \alpha$ immunointensity in endometrial stroma and ER $\alpha$ mRNA expression. There could be two possible mechanisms for how global AR inactivation reversed increased ER $\alpha$ induced by PTEN deletion. First, AR directly modifies ER $\alpha$ expression in the uterus. Second, AR could interact with PTEN to indirectly modify ER $\alpha$ expression. Supporting the first mechanism, testosterone was shown to suppress ER $\alpha$ expression in mammary tissue (Zhou et al. 2000). However, our study has shown that testosterone treatment in the OVX PTENKO female caused a marked increase in ER $\alpha$ expression in the PTENKO uterus in all of the cells. The second mechanism is supported by findings in both the prostate and breast cancers (Wang et al. 2011), whereby AR-mediated actions modify PTEN (noting our model still has one functional PTEN allele) and results in alterations in ER $\alpha$ expression (Vilgelm et al. 2006). Either or both of these mechanisms could represent the molecular pathway involved in the impact of AR-mediated androgen action on PTEN inactivation induced uterine cancer. Clearly, further mechanistic studies are warranted to elucidate the role of AR-mediated androgen action at various stages of uterine carcinogenesis.

Our study is also informative about the role of $\mathrm{P}_{4}$ action in uterine carcinogenesis. Whereas progestins are known to protect against uterine cancer (Martin et al. 1973a, Persson 1996), we observed unexpectedly (given that $\mathrm{P}_{4}$ protects against uterine cancer) that serum $\mathrm{P}_{4}$ was significantly increased in PTENKO females compared to other genotypes. However, in our study the PTENKO uterus did not seem to benefit from the increased serum $\mathrm{P}_{4}$ levels although PR was expressed in all of the cells of the uterus, consistent with a previous finding that heterozygous PTEN inactivation induced uterine cancer was unresponsive to progestin treatments (Fyles et al. 2008). Nevertheless, our finding of increased serum $\mathrm{P}_{4}$ is consistent with a previous study showing increased CL numbers in the ovaries of the granulosa cell specific PTEN inactivation in mice (Fan et al. 2008), a finding that might explain increased serum $\mathrm{P}_{4}$ as CLs characteristically secrete $\mathrm{P}_{4}$. Conversely, complete AR inactivation in female mice results in reduced CL numbers compared with WT (Walters et al. 2007). Therefore, we analyzed CL numbers in our experimental females and observed that CL numbers were significantly increased in the ovaries of PTENKO females and this increase was also prevented by simultaneous AR inactivation in PTENARKO females.

Published by Bioscientifica Ltd. 
While there were no obvious differences in PR immunopositivity between the PTENKO and PTENARKO uterus, we showed that testosterone treatment in OVX PTENKO females increased PR immunopositivity throughout the PTENKO uterus. However, this could be due to the supraphysiological levels of testosterone produced by our testosterone implant, which may not reflect normal physiological effects of testosterone in intact mouse.

Among the many non-uterine abnormalities found in our PTEN inactivated mice, mammary tumors were the most common. A majority (54\%) of PTENKO and PTENARKO females displayed abnormal mammary glands that contained mainly lymphomas and fibroadenomas (Stambolic et al. 2000) as well as a benign pathology of inappropriate mammary alveolarization and milk production in virgin mice (Conneely et al. 2003). In mammary pathology, however, there were no significant differences between PTENKO and PTENARKO females. Previously, the role of androgens in breast cancer has been controversial but a recent study has suggested an inhibitory role of androgens in breast cancer (Simanainen et al. 2012). However, the present study did not show a protective role of androgen actions via AR on PTENKO induced breast cancer incidence compared to PTENARKO. This suggests a different mechanism such as involving the increased serum $\mathrm{P}_{4}$ level in PTENKO but not in PTENARKO females. While controversial, there has been a suggestion that $\mathrm{P}_{4}$ may promote breast tissue proliferation and could thereby increase the risk in PTENKO to the same level as in PTENARKO (Russo et al. 2000). In addition, the different mechanisms of inducing experimental breast cancers (i.e., PTEN inactivation vs overactive ERBB2 signaling vs chemically induced) could explain the findings. Finally, while overactive ERBB2 and chemically induced cancers are mainly carcinomas, the PTENKO induced fibroadenomas. Mammary glands with alveolarization could be due to the increased $\mathrm{P}_{4}$ levels, as $\mathrm{P}_{4}$ is known to cause alveolarization and milk production (Conneely et al. 2003). A previous study also observed increased mammary gland alveolarization in heterozygous PTENKO females, but $\mathrm{P}_{4}$ levels were not determined (Guigon et al. 2011). We also showed that less PTENARKO females appeared to have alveolarized mammary glands compared to PTENKO, further supporting the reduced $\mathrm{P}_{4}$ levels in PTENARKO compared to PTENKO females.

As we have used global PTEN and/or AR inactivation in our experimental mice, we found changes in organ weights other than the uterus such as the adrenal glands, breast, liver, lung, ovaries, pancreas, and spleen. These findings were supported by previous studies using PTEN inactivated mouse models. PTEN inactivation causes hyperplastic adrenal glands, an enlarged liver, epithelial hyperplasia in the lung, altered ovarian physiology, and an increased spleen weight (Knobbe et al. 2008). From our study, the role of androgens in these organs remain speculative, however, androgens may play an organspecific role of inducing or inhibiting pathogenesis, which requires further investigations.

In conclusion, our study has demonstrated that the global AR inactivation reduced PTEN inactivation induced uterine carcinogenesis by decreasing stroma ER $\alpha$ expression and thereby estrogen sensitivity. However, further investigation is required to understand how PTEN and AR modify ER $\alpha$ expression in the uterus. Most importantly, our study provides first in vivo evidence that androgen actions via AR play a significant role in the uterine cancer development and raises the hypothesis that antiandrogen therapy may have a role in the prevention and early stages of uterine carcinogenesis or its treatment.

\section{Declaration of interest}

The authors declare that there is no conflict of interest that could be perceived as prejudicing the impartiality of the research reported.

\section{Funding}

This research did not receive any specific grant from any funding agency in the public, commercial or not-for-profit sector.

\section{References}

An HJ, Lee YH, Cho NH, Shim JY, Kim JY, Lee C \& Kim SJ 2002 Alteration of PTEN expression in endometrial carcinoma is associated with downregulation of cyclin-dependent kinase inhibitor, p27. Histopathology 41 437-445. (doi:10.1046/j.1365-2559.2002.01455.x)

Apparao KB, Lovely LP, Gui Y, Lininger RA \& Lessey BA 2002 Elevated endometrial androgen receptor expression in women with polycystic ovarian syndrome. Biology of Reproduction 66 297-304. (doi:10.1095/ biolreprod66.2.297)

Bender D, Buekers T \& Leslie KK 2011 Hormones and receptors in endometrial cancer. Proceedings in Obstetrics and Gynecology 2 1-25.

Byun DS, Ahmed N, Nasser S, Shin J, Al-Obaidi S, Goel S, Corner GA, Wilson AJ, Flanagan DJ, Williams DS et al. 2011 Intestinal epithelial-specific PTEN inactivation results in tumor formation. American Journal of Physiology. Gastrointestinal and Liver Physiology 301 G856-G864 (doi:10.1152/ajpgi.00178.2011)

Carver BS, Chapinski C, Wongvipat J, Hieronymus H, Chen Y, Chandarlapaty S, Arora VK, Le C, Koutcher J, Scher H et al. 2011 Reciprocal feedback regulation of PI3K and androgen receptor signaling in PTEN-deficient prostate cancer. Cancer Cell 19 575-586. (doi:10.1016/j.ccr.2011.04.008)

Conneely OM, Jericevic BM \& Lydon JP 2003 Progesterone receptors in mammary gland development and tumorigenesis. Journal of Mammary Gland Biology and Neoplasia 8 205-214. (doi:10.1023/ A:1025952924864)
(C) 2015 Society for Endocrinology Printed in Great Britain 
Dahia PL 2000 PTEN, a unique tumor suppressor gene. Endocrine-Related Cancer 7 115-129. (doi:10.1677/erc.0.0070115)

Fan HY, Liu Z, Cahill N \& Richards JS 2008 Targeted disruption of Pten in ovarian granulosa cells enhances ovulation and extends the life span of luteal cells. Molecular Endocrinology 22 2128-2140. (doi:10.1210/me. 2008-0095)

Fang Z, Zhang T, Dizeyi N, Chen S, Wang H, Swanson KD, Cai C, Balk SP \& Yuan X 2012 Androgen receptor enhances p27 degradation in prostate cancer cells through rapid and selective TORC2 activation. Journal of Biological Chemistry 287 2090-2098. (doi:10.1074/jbc.M111.323303)

Fyles A, Wood G, Li M, Manoukian AS, Gowing K, Khokha R, Chapman W \& Tsao MS 2008 Neither ovariectomy nor progestin treatment prevents endometrial neoplasia in pten ${ }^{+/-}$mice. Gynecologic Oncology 108 395-401. (doi:10.1016/j.ygyno.2007.10.033)

Gambrell RD Jr, Bagnell CA \& Greenblatt RB 1983 Role of estrogens and progesterone in the etiology and prevention of endometrial cancer: review. American Journal of Obstetrics and Gynecology 146 696-707.

Gao YR, Walters KA, Desai R, Zhou H, Handelsman DJ \& Simanainen U 2014 Androgen receptor inactivation resulted acceleration in pubertal mammary gland growth, up-regulation of ER $\alpha$ expression and Wnt/ $\beta$-catenin signalling in female mice. Endocrinology 155 4951-4963. (doi:10.1210/en.2014-1226)

Guigon CJ, Kim DW, Willingham MC \& Cheng SY 2011 Mutation of thyroid hormone receptor- $\beta$ in mice predisposes to the development of mammary tumors. Oncogene 30 3381-3390. (doi:10.1038/onc.2011.50)

Harwood DT \& Handelsman DJ 2009 Development and validation of a sensitive liquid chromatography-tandem mass spectrometry assay to simultaneously measure androgens and estrogens in serum without derivatization. Clinica Chimica Acta 409 78-84. (doi:10.1016/j.cca. 2009.09.003)

Hayashi S, Lewis P, Pevny L \& McMahon AP 2002 Efficient gene modulation in mouse epiblast using a Sox2Cre transgenic mouse strain. Mechanisms of Development 119 (Suppl 1) S97-S101. (doi:10.1016/ S0925-4773(03)00099-6)

Hillier SG, Whitelaw PF \& Smyth CD 1994 Follicular oestrogen synthesis the 'two-cell, two-gonadotrophin' model revisited. Molecular and Cellular Endocrinology 100 51-54. (doi:10.1016/0303-7207(94)90278-X)

Huhtinen K, Desai R, Stahle M, Salminen A, Handelsman DJ, Perheentupa A $\&$ Poutanen M 2012 Endometrial and endometriotic concentrations of estrone and estradiol are determined by local metabolism rather than circulating levels. Journal of Clinical Endocrinology and Metabolism 97 4228-4235. (doi:10.1210/jc.2012-1154)

Ito K, Suzuki T, Akahira J, Moriya T, Kaneko C, Utsunomiya H, Yaegashi N, Okamura K \& Sasano H 2002 Expression of androgen receptor and $5 \alpha$-reductases in the human normal endometrium and its disorders. International Journal of Cancer 99 652-657. (doi:10.1002/ijc.10394)

Knobbe CB, Lapin V, Suzuki A \& Mak TW 2008 The roles of PTEN in development, physiology and tumorigenesis in mouse models: a tissueby-tissue survey. Oncogene 27 5398-5415. (doi:10.1038/onc.2008.238)

Lee H, Choi HJ, Kang CS, Lee HJ, Lee WS \& Park CS 2012 Expression of miRNAs and PTEN in endometrial specimens ranging from histologically normal to hyperplasia and endometrial adenocarcinoma. Modern Pathology 25 1508-1515. (doi:10.1038/modpathol.2012.111)

Lesche R, Groszer M, Gao J, Wang Y, Messing A, Sun H, Liu X \& Wu H 2002 Cre/loxP-mediated inactivation of the murine Pten tumor suppressor gene. Genesis 32 148-149. (doi:10.1002/gene.10036)

Levine RL, Cargile CB, Blazes MS, van Rees B, Kurman RJ \& Ellenson LH 1998 PTEN mutations and microsatellite instability in complex atypical hyperplasia, a precursor lesion to uterine endometrioid carcinoma. Cancer Research 58 3254-3258.

Li J, Simpson L, Takahashi M, Miliaresis C, Myers MP, Tonks N \& Parsons R 1998 The PTEN/MMAC1 tumor suppressor induces cell death that is rescued by the AKT/protein kinase B oncogene. Cancer Research $\mathbf{5 8}$ 5667-5672.

Li P, Nicosia SV \& Bai W 2001 Antagonism between PTEN/MMAC1/TEP-1 and androgen receptor in growth and apoptosis of prostatic cancer cells. Journal of Biological Chemistry 276 20444-20450. (doi:10.1074/jbc. M010226200)

Li G, Robinson GW, Lesche R, Martinez-Diaz H, Jiang Z, Rozengurt N, Wagner KU, Wu DC, Lane TF, Liu X et al. 2002 Conditional loss of PTEN leads to precocious development and neoplasia in the mammary gland. Development 129 4159-4170.

Lian Z, De Luca P \& Di Cristofano A 2006 Gene expression analysis reveals a signature of estrogen receptor activation upon loss of Pten in a mouse model of endometrial cancer. Journal of Cellular Physiology $\mathbf{2 0 8}$ 255-266. (doi:10.1002/jcp.20681)

Liang J, Zubovitz J, Petrocelli T, Kotchetkov R, Connor MK, Han K, Lee JH, Ciarallo S, Catzavelos C, Beniston R et al. 2002 PKB/Akt phosphorylates p27, impairs nuclear import of p27 and opposes p27-mediated G1 arrest. Nature Medicine 8 1153-1160. (doi:10.1038/nm761)

Liaw D, Marsh DJ, Li J, Dahia PL, Wang SI, Zheng Z, Bose S, Call KM, Tsou HC, Peacocke M et al. 1997 Germline mutations of the PTEN gene in Cowden disease, an inherited breast and thyroid cancer syndrome. Nature Genetics 16 64-67. (doi:10.1038/ng0597-64)

Lobo RA, Granger L, Goebelsmann U \& Mishell DR Jr 1981 Elevations in unbound serum estradiol as a possible mechanism for inappropriate gonadotropin secretion in women with PCO. Journal of Clinical Endocrinology and Metabolism 52 156-158. (doi:10.1210/jcem-52-1-156)

Martin L, Das RM \& Finn CA 1973a The inhibition by progesterone of uterine epithelial proliferation in the mouse. Journal of Endocrinology $\mathbf{5 7}$ 549-554. (doi:10.1677/joe.0.0570549)

Martin L, Finn CA \& Trinder G 1973b Hypertrophy and hyperplasia in the mouse uterus after oestrogen treatment: an autoradiographic study. Journal of Endocrinology 56 133-144. (doi:10.1677/joe.0.0560133)

McGrath M, Lee IM, Hankinson SE, Kraft P, Hunter DJ, Buring J \& De Vivo I 2006 Androgen receptor polymorphisms and endometrial cancer risk. International Journal of Cancer 118 1261-1268. (doi:10.1002/ijc.21436)

McNamara KM, Harwood DT, Simanainen U, Walters KA, Jimenez M \& Handelsman DJ 2010 Measurement of sex steroids in murine blood and reproductive tissues by liquid chromatography-tandem mass spectrometry. Journal of Steroid Biochemistry and Molecular Biology 121 611-618. (doi:10.1016/j.jsbmb.2010.02.001)

McNamara KM, Yoda T, Miki Y, Chanplakorn N, Wongwaisayawan S, Incharoen P, Kongdan Y, Wang L, Takagi K, Mayu T et al. 2013 Androgenic pathway in triple negative invasive ductal tumors: its correlation with tumor cell proliferation. Cancer Science 104 639-646. (doi:10.1111/cas.12121)

Mulholland DJ, Tran LM, Li Y, Cai H, Morim A, Wang S, Plaisier S, Garraway IP, Huang J, Graeber TG et al. 2011 Cell autonomous role of PTEN in regulating castration-resistant prostate cancer growth. Cancer Cell 19 792-804. (doi:10.1016/j.ccr.2011.05.006)

Nagamani M, Hannigan EV, Dillard EA Jr \& Van Dinh T 1986 Ovarian steroid secretion in postmenopausal women with and without endometrial cancer. Journal of Clinical Endocrinology and Metabolism 62 508-512. (doi:10.1210/jcem-62-3-508)

Notini AJ, Davey RA, McManus JF, Bate KL \& Zajac JD 2005a Genomic actions of the androgen receptor are required for normal male sexual differentiation in a mouse model. Journal of Molecular Endocrinology 35 547-555. (doi:10.1677/jme.1.01884)

Notini AJ, Davey RA, McManus JF, Bate KL \& Zajac JD 2005b Genomic actions of the androgen receptor are required for normal male sexual differentiation in a mouse model. Journal of Molecular Endocrinology 35 547-555. (doi:10.1677/jme.1.01884)

Nycum LR, Smith LM, Farley JH, Kost ER, Method MW \& Birrer MJ 2001 The role of p27 in endometrial carcinoma. Gynecologic Oncology 81 242-246. (doi:10.1006/gyno.2001.6144)

Persson I 1996 Cancer risk in women receiving estrogen-progestin replacement therapy. Maturitas 23 (Suppl) S37-S45. (doi:10.1016/03785122(96)01010-9)

Quigley CA, De Bellis A, Marschke KB, el-Awady MK, Wilson EM \& French FS 1995 Androgen receptor defects: historical, clinical, and molecular perspectives. Endocrine Reviews 16 271-321. 
Risinger JI, Hayes AK, Berchuck A \& Barrett JC 1997 PTEN/MMAC1 mutations in endometrial cancers. Cancer Research 57 4736-4738.

Russo J, Hu YF, Yang X \& Russo IH 2000 Developmental, cellular, and molecular basis of human breast cancer. Journal of the National Cancer Institute. Monographs 27 17-37. (doi:10.1093/oxfordjournals. jncimonographs.a024241)

Schmidt WN \& Katzenellenbogen BS 1979 Androgen-uterine interactions: an assessment of androgen interaction with the testosterone- and estrogen-receptor systems and stimulation of uterine growth and progesterone-receptor synthesis. Molecular and Cellular Endocrinology 15 91-108. (doi:10.1016/0303-7207(79)90010-8)

Sgambato A, Cittadini A, Faraglia B \& Weinstein IB 2000 Multiple functions of p27(Kip1) and its alterations in tumor cells: a review. Journal of Cellular Physiology 183 18-27. (doi:10.1002/(SICI)1097-4652(200004) 183:1<18::AID-JCP3 > 3.0.CO;2-S)

Simanainen U, Allan CM, Lim P, McPherson S, Jimenez M, Zajac JD, Davey RA \& Handelsman DJ 2007 Disruption of prostate epithelial androgen receptor impedes prostate lobe-specific growth and function. Endocrinology 148 2264-2272. (doi:10.1210/en.2006-1223)

Simanainen U, McNamara K, Gao YR \& Handelsman DJ 2009 Androgen sensitivity of prostate epithelium is enhanced by postnatal androgen receptor inactivation. American Journal of Physiology. Endocrinology and Metabolism 296 E1335-E1343. (doi:10.1152/ajpendo.00017.2009)

Simanainen U, Brogley M, Gao YR, Jimenez M, Harwood DT, Handelsman DJ \& Robins DM 2011 Length of the human androgen receptor glutamine tract determines androgen sensitivity in vivo. Molecular and Cellular Endocrinology 342 81-86. (doi:10.1016/j.mce.2011.05.011)

Simanainen U, Gao YR, Walters KA, Watson G, Desai R, Jimenez M \& Handelsman DJ 2012 Androgen resistance in female mice increases susceptibility to DMBA-induced mammary tumors. Hormones \& Cancer 3 113-124. (doi:10.1007/s12672-012-0107-9)

Slingerland J \& Pagano M 2000 Regulation of the cdk inhibitor p27 and its deregulation in cancer. Journal of Cellular Physiology 183 10-17. (doi:10.1002/(SICI)1097-4652(200004)183:1 < 10::AID-JCP2>3.0.CO;2-I)

Smyczek-Gargya B \& Geppert M 1992 Endometrial cancer associated with polycystic ovaries in young women. Pathology, Research and Practice 188 946-948 (discussion 948-950). (doi:10.1016/S0344-0338(11)80256-6)

Somboonporn W, Davis SR, National H \& Medical Research C 2004 Testosterone effects on the breast: implications for testosterone therapy for women. Endocrine Reviews 25 374-388. (doi:10.1210/er.2003-0016)

Stambolic V, Suzuki A, de la Pompa JL, Brothers GM, Mirtsos C, Sasaki T, Ruland J, Penninger JM, Siderovski DP \& Mak TW 1998 Negative regulation of $\mathrm{PKB} / \mathrm{Akt}$-dependent cell survival by the tumor suppressor PTEN. Cell 95 29-39. (doi:10.1016/S0092-8674(00)81780-8)

Stambolic V, Tsao MS, Macpherson D, Suzuki A, Chapman WB \& Mak TW 2000 High incidence of breast and endometrial neoplasia resembling human Cowden syndrome in pten ${ }^{+/-}$mice. Cancer Research 60 3605-3611.

Stocco C, Telleria C \& Gibori G 2007 The molecular control of corpus luteum formation, function, and regression. Endocrine Reviews $\mathbf{2 8}$ 117-149. (doi:10.1210/er.2006-0022)

Suzuki A, de la Pompa JL, Stambolic V, Elia AJ, Sasaki T, del Barco Barrantes I, Ho A, Wakeham A, Itie A, Khoo W et al. 1998 High cancer susceptibility and embryonic lethality associated with mutation of the PTEN tumor suppressor gene in mice. Current Biology 8 1169-1178. (doi:10.1016/ S0960-9822(07)00488-5)

Tashiro H, Blazes MS, Wu R, Cho KR, Bose S, Wang SI, Li J, Parsons R \& Ellenson LH 1997 Mutations in PTEN are frequent in endometrial carcinoma but rare in other common gynecological malignancies. Cancer Research 57 3935-3940.

Tuckerman EM, Okon MA, Li T \& Laird SM 2000 Do androgens have a direct effect on endometrial function? An in vitro study Fertility and Sterility 74 771-779. (doi:10.1016/S0015-0282(00)00711-1)

Vignarajan S, Xie C, Yao M, Sun Y, Simanainen U, Sved P, Liu T \& Dong Q 2014 Loss of PTEN stabilizes the lipid modifying enzyme cytosolic phospholipase $\mathrm{A}(2) \alpha$ via AKT in prostate cancer cells. Oncotarget 5 6289-6299.

Vilgelm A, Lian Z, Wang H, Beauparlant SL, Klein-Szanto A, Ellenson LH \& Di Cristofano A 2006 Akt-mediated phosphorylation and activation of estrogen receptor $\alpha$ is required for endometrial neoplastic transformation in Pten ${ }^{+/-}$mice. Cancer Research 66 3375-3380. (doi:10.1158/ 0008-5472.CAN-05-4019)

Walters KA, Allan CM, Jimenez M, Lim PR, Davey RA, Zajac JD, Illingworth P \& Handelsman DJ 2007 Female mice haploinsufficient for an inactivated androgen receptor (AR) exhibit age-dependent defects that resemble the AR null phenotype of dysfunctional late follicle development, ovulation, and fertility. Endocrinology 148 3674-3684. (doi:10.1210/en.2007-0248)

Walters KA, McTavish KJ, Seneviratne MG, Jimenez M, McMahon AC, Allan CM, Salamonsen LA \& Handelsman DJ 2009 Subfertile female androgen receptor knockout mice exhibit defects in neuroendocrine signaling, intraovarian function, and uterine development but not uterine function. Endocrinology 150 3274-3282. (doi:10.1210/ en.2008-1750)

Walters KA, Simanainen U \& Handelsman DJ 2010 Molecular insights into androgen actions in male and female reproductive function from androgen receptor knockout models. Human Reproduction Update 16 543-558. (doi:10.1093/humupd/dmq003)

Waltregny D, Leav I, Signoretti S, Soung P, Lin D, Merk F, Adams JY, Bhattacharya N, Cirenei N \& Loda M 2001 Androgen-driven prostate epithelial cell proliferation and differentiation in vivo involve the regulation of p27. Molecular Endocrinology 15 765-782. (doi:10.1210/ mend.15.5.0640)

Wang Y, Romigh T, He X, Tan MH, Orloff MS, Silverman RH, Heston WD \& Eng C 2011 Differential regulation of PTEN expression by androgen receptor in prostate and breast cancers. Oncogene $304327-4338$. (doi:10.1038/onc.2011.144)

Watanabe J, Sato H, Kanai T, Kamata Y, Jobo T, Hata H, Fujisawa T, Ohno E, Kameya T \& Kuramoto H 2002 Paradoxical expression of cell cycle inhibitor p27 in endometrioid adenocarcinoma of the uterine corpus correlation with proliferation and clinicopathological parameters. British Journal of Cancer 87 81-85. (doi:10.1038/sj.bjc.6600434)

Zhou J, Ng S, Adesanya-Famuiya O, Anderson K \& Bondy CA 2000 Testosterone inhibits estrogen-induced mammary epithelial proliferation and suppresses estrogen receptor expression. FASEB Journal 14 1725-1730. (doi:10.1096/fj.99-0863com)

Received in final form 1 July 2015

Accepted 6 July 2015 http://erc.endocrinology-journals.org

DOI: 10.1530/ERC-15-0203
(C) 2015 Society for Endocrinology Printed in Great Britain
Published by Bioscientifica Ltd 